\title{
PENGARUH KOMPETENSI DAN PENEMPATAN TERHADAP KINERJA KARYAWAN PT. ALAM SUTERA REALTY TBK
}

\author{
Ella Siti Chaeriah *) \\ *) Dosen Program Studi Manajemen FE UNKRIS \\ Alamat: Kampus UNKRIS, Jatiwaringin Jakarta Timut \\ Email : Ellasitichaeriah@gmail.com
}

\begin{abstract}
Increasing competency in supporting the success of employees achieving the target of work provided is an important factor and is supported by the suitability of existing job requirements. This study aims to analyze the simultaneous and partial influence of competence and placement on the performance of employees at PT. Alam Sutera Realty Tbk involving 74 employees. The results of the study show that there are positive effects both simultaneously and partially on competence and placement on the performance of employees at PT. Alam Sutera Realty Tbk.
\end{abstract}

Ke words : Competency, placement, and employee performance

\section{PENDAHULUAN}

Organisasi

dan

karyawan

merupakan dua hal yang saling membutuhkan. Jika karyawan berhasil membawa kemajuan bagi perusahaan, keuntungan yang diperoleh akan dipetik oleh kedua belah pihak. Bagi karyawan, keberhasilan merupakan aktualisasi potensi diri sekaligus peluang untuk memenuhi kebutuhan hidupnya. Sedangkan bagi perusahaan, keberhasilan merupakan sarana menuju pertumbuhan dan perkembangan perusahaan itu sendiri. Langkah awal dalam menghasilkan sumber daya manusia yang terampil dan handal perlu adanya suatu perencanaan dalam menentukan karyawan yang akan mengisi pekerjaan yang ada dalam perusahaan. Keberhasilan dalam pengadaan tenaga kerja terletak pada ketepatan dalam penempatan karyawan, baik penempatan karyawan baru maupun karyawan lama pada posisi jabatan baru.

\section{LANDASAN TEORI}

\section{Kompetensi}

Dharma (2009) istilah kompetensi mengacu kepada dimensi perilaku dari sebuah peran perilaku yang diperlikan seseorang untuk dapat melaksanakan pekerjaannya secara memuaskan. Sebagaimana definisi kompetensi diatas, dapat disimpulkan kompetensi mencakup karakteristik perilaku yang dapat menunjukkan perbedaan antara karyawan yang berkinerja tinggi yang dalam konteks ini menyangkut prestasi yang dihasilkan. Lebih jauh Dharma (2009) mengungkapkan bahwa kompetensi adalah apa yang dibawa oleh seseorang ke dalam pekerjaannya dalam bentuk jenis dan tingkatan perilaku yang berbeda. Hal ini harus dibedakan dari kemampuan tertentu (pengetahuan, keahlian dan kepiawaian) yang dibutuhkan untuk melaksanakan berbagai tugas yang berhubungan dengan suatu pekerjaan. Kompetensi menentukan aspek-aspek proses dari hasil suatu pekerjaan. 


\section{Penempatan}

Rosidah (2009) mendefinisikan penempatan sebagai suatu kebijakan yang diambil oleh pimpinan suatu instansi, atau bagian personalia untuk menentukan seseorang karyawan masih tetap atau tidak ditempatkan pada suatu posisi atau jabatan tertentu berdasarkan pertimbangan keahlian, keterampilan atau kualifikasi tertentu. Rivai (2009) mendefinisikan penempatan karyawan adalah penugasan atau penugasan kembali seorang karyawan kepada pekerjaan barunya. Siagian (2008) mengungkapkan penempatan tidak hanya berlaku bagi para karyawan baru, akan tetapi berlaku pula bagi karyawan lama yang mengalami alih tugas dan mutasi.

\section{Kinerja Karyawan}

Sutrisno (2010) menyatakan bahwa kinerja diartikan sebagai "kesuksesan seseorang dalam melaksanakan tugas". Lebih lanjut Sutrisno (2010) mengemukakan kinerja sebagai "hasil kerja yang dapat dicapai oleh seseorang atau kelompok orang dalam suatu organisasi, sesuai dengan wewenang dan tanggungjawab masing-masing, dalam rangka upaya mencapai tujuan organisasi bersangkutan secara legal, tidak melanggar hukum, dan sesuai dengan moral maupun etika.

Dalam kutipannya Sutrisno (2010) mengemukakan kinerja adalah "bagaimana seseorang diharapkan dapat berfungsi dan berperilaku sesuai dengan tugas yang telah dibebankan kepadanya”. Pendapat lain juga dikemukakan oleh Sutrisno (2010) mengemukakan kinerja karyawan sebagai "prestasi yang diperoleh seseorang dalam melakukan tugas". Oleh karena itu, keberhasilan organisasi dalam mencapai tujuannya tergantung dari seberapa baik kinerja karyawan yang dimiliki.

\section{METODE PENELITIAN}

\section{Populasi dan Sampel}

Umar (2008) mendefinisikan populasi sebagai kumpulan elemen yang mempunyai karakteristik tertentu yang sama dan mempunyai kesempatan yang sama untuk dipilih menjadi anggota sampel. Populasi dalam penelitian ini yaitu sebanyak 74 orang karyawan. Kemudian sampel menurut Suharsimi (2009) adalah sebagian atau wakil populasi yang diteliti. Jumlah dalam pengambilan sampelnya adalah sebanyak 50 orang karyawan. Adapun teknik sampling yang digunakan adalah simple random sampling. Yang dimaksud dengan simple random sampling (sampel acak) adalah cara pengambilan sampel dari anggota populasi dengan menggunakan acak tanpa memperhatikan strata (tingkatan) dalam anggota populasi tersebut.

\section{Metode Pengumpulan Data}

Penelitian ini dimaksudkan untuk menguji hipotesis dengan menggunakan analisa regresi sederhana. Dengan menggunakan analisa statistik ini maka akan diketahuipengaruh parsial maupun simultan variabel kompetensi, dan variabel penempatan terhadap variabel kinerja karyawan sehingga menghasilkan kesimpulan yang akan memperjelas terhadap variabel yang diteliti.

Sumber data yang dibutuhkan dalam penelitian ini adalah data primer. Menurut Sugiyono (2010) yang menyatakan bahwa sumber data primer yaitu sumber data yang langsung memberikan data kepada pengumpul data. Data primer diperoleh dengan cara observasi dan wawancara dengan karyawan PT. Alam Sutera Realty Tbk.

Butir-butir pertanyaan yang dibuat dalam bentuk pilihan ganda, yang setiap butirnya berisi lima jawaban. Nilai jawaban yang diberikan memakai sistem 
skala Likert dengan skala 1 sampai dengan 5, penjelasan masing-masing jawaban pada skala likert dapat dilihat pada Tabel 1.

Tabel 1. Skala Questioner

\begin{tabular}{cc}
\hline Skala & Keterangan \\
\hline 5 & Sangat Setuju (SS) \\
4 & Setuju (S) \\
3 & Kurang Setuju (KS) \\
2 & Tidak Setuju (TS) \\
1 & SangatTidak Setuju (STS) \\
\hline
\end{tabular}

Tabel 2. Variabel dan Indikator Penelitian

\begin{tabular}{|c|c|c|c|}
\hline VARIABEL & SUB VARIABEL & INDIKATOR & $\begin{array}{c}\text { SKALA } \\
\text { DIKONVERSI }\end{array}$ \\
\hline \multirow[t]{3}{*}{ KOMPETENSI } & Pengetahuan & $\begin{array}{l}\text { - Pengetahuan terhadap } \\
\text { tugas yang diberikan }\end{array}$ & Ordinal \\
\hline & Keterampilan & $\begin{array}{l}\text { - Mampu melaksanakan } \\
\text { tugas yang diberikan, }\end{array}$ & \\
\hline & Sikap/perilaku & $\begin{array}{l}\text { - Disiplin dan teliti } \\
\text { dalam melaksanakan } \\
\text { tugas }\end{array}$ & \\
\hline \multirow[t]{4}{*}{ PENEMPATAN } & Pengetahuan & $\begin{array}{l}\text { Pendidikan, } \\
\text { pengalaman }\end{array}$ & Ordinal \\
\hline & Minat & $\begin{array}{l}\text { Kondisi pekerjaan, } \\
\text { sistem pendukung, } \\
\text { pribadi pekerja }\end{array}$ & \\
\hline & Keterampilan & - kecakapan & \\
\hline & Pengalaman & $\begin{array}{l}\text { - Pelatihan dan lama } \\
\text { bekerja }\end{array}$ & \\
\hline \multirow[t]{4}{*}{$\begin{array}{l}\text { KINERJA } \\
\text { KARYAWAN }\end{array}$} & Kualitas kerja & $\begin{array}{l}\text { Ketepatan dalam } \\
\text { melaksanakan tugas } \\
\text { dan pekerjaan, } \\
\text { Ketelitian dalam } \\
\text { melaksanakan } \\
\text { tugasnya, Kerapian } \\
\text { dalam melaksanakan } \\
\text { tugas dan } \\
\text { pekerjaannya }\end{array}$ & Ordinal \\
\hline & Kuantitas kerja & $\begin{array}{l}\text { - Banyaknya jumlah } \\
\text { kegagalan, Banyaknya } \\
\text { jumlah keberhasilan }\end{array}$ & \\
\hline & $\begin{array}{l}\text { Penggunaan waktu } \\
\text { dalam bekerja }\end{array}$ & $\begin{array}{l}\text { - Absensi, } \\
\text { keterlambatan, masa } \\
\text { kerja }\end{array}$ & \\
\hline & Kerjasama & $\begin{array}{l}\text { - Hubungan dengan } \\
\text { rekan sekerja, Upaya } \\
\text { individu dalam } \\
\text { mensukseskan kinerja } \\
\text { tim }\end{array}$ & \\
\hline
\end{tabular}

Sumber : Data Primer, diolah tahun 2018 


\section{Metode Analisis Data}

Metode analisis data yang digunakan adalah regresi linear sederhana dan regresi linear berganda. Analisis linear sederhana digunakan untuk menganalisis pengaruh kompetensi dan penempatan secara parsial terhadap kinerja karyawan, sedangkan analisis regresi linear berganda digunakan untuk menganalisis pengaruh kompetensi dan penempatan secara bersama-sama terhadap kinerja karyawan.

\section{HASIL DAN PEMBAHASAN}

\section{Hasil Penelitian}

\section{Uji Kualitas Data}

\section{Uji Validitas}

Penguji validitas ini dilakukan untuk menguji apakah tiap-tiap butir pernyataan telah mewakili indikator yang akan diselidiki. Menurut Masrun yang dikutip oleh Sugiyono, 2014, menyatakan bahwa biasanya syarat minimum untuk dianggap valid adalah $r$ $=0,30$. Jadi apabila korelasi antara butir-butir dengan skor total kurang dari 0,30 maka butiran dalam instrument tersebut dinyatakan tidak valid. Uji validitas dilakukan dengan melihat korelasi antar skor masing-masing item pernyataan dengan skor total.

\section{a. Uji Validitas Instrumen Kompetensi}

Dari hasil perhitungan korelasi skor tiap butir pernyataan instrument kompetensi dari 74 responden dengan jumlah pernyataan masing-masing variabel 10 pernyataan dengan total skor setiap responden diperoleh hasil disajikan dalam Tabel 3 sebagai berikut :

Tabel 3. Uji Validitas Variabel Kompetensi

\begin{tabular}{cccc}
\hline Kuesioner & R hitung & Rkritis & Kesimpulan \\
\hline Instrumen No. 1 & 0,909 & 0,284 & Valid \\
Instrumen No. 2 & 0,875 & 0,284 & Valid \\
Instrumen No. 3 & 0,900 & 0,284 & Valid \\
Instrumen No. 4 & 0,902 & 0,284 & Valid \\
Instrumen No. 5 & 0,888 & 0,284 & Valid \\
Instrumen No. 6 & 0,904 & 0,284 & Valid \\
Instrumen No. 7 & 0,874 & 0,284 & Valid \\
Instrumen No. 8 & 0,821 & 0,284 & Valid \\
Instrumen No. 9 & 0,821 & 0,284 & Valid \\
Instrumen No. 10 & 0,935 & 0,284 & Valid
\end{tabular}

Berdasarkan Tabel 3, dapat dilihat variabel kompetensi hasilnya adalah valid.

bahwa dari 10 butir pernyataan dari

\section{b. Uji Validitas Instrumen Penempatan}

Dari hasil perhitungan koefisien korelasi skor tiap butir pernyataan instrument penempatan dari 74 responden dengan jumlah pernyataan masing-masing variabel 10 pernyataan dengan total skor setiap responden hasil disajikan dalam Tabel 4 sebagai berikut 
Tabel 4. Uji Validitas Instrumen Penempatan

\begin{tabular}{cccc}
\hline Kuesioner & R hitung & R kritis & Kesimpulan \\
\hline Instrumen No. 1 & 0,889 & 0,284 & Valid \\
Instrumen No. 2 & 0,923 & 0,284 & Valid \\
Instrumen No. 3 & 0,879 & 0,284 & Valid \\
Instrumen No. 4 & 0,890 & 0,284 & Valid \\
Instrumen No. 5 & 0,857 & 0,284 & Valid \\
Instrumen No. 6 & 0,912 & 0,284 & Valid \\
Instrumen No. 7 & 0,899 & 0,284 & Valid \\
Instrumen No. 8 & 0,918 & 0,284 & Valid \\
Instrumen No. 9 & 0,896 & 0,284 & Valid \\
Instrumen No. 10 & 0,942 & 0,284 & Valid \\
\hline
\end{tabular}

Sumber : Data Primer, diolah tahun 2018

Berdasarkan Tabel 4, dapat dilihat bahwa dari 10 butir pernyataan dari variabel penempatan hasilnya adalah valid.

\section{c. Uji Validitas Instrumen Kinerja Karyawan}

Tabel 5. Uji Validitas Instrumen Kinerja karyawan

\begin{tabular}{cccc}
\hline Kuesioner & R hitung & Rkritis & Kesimpulan \\
\hline Instrumen No. 1 & 0,922 & 0,284 & Valid \\
Instrumen No. 2 & 0,877 & 0,284 & Valid \\
Instrumen No. 3 & 0,917 & 0,284 & Valid \\
Instrumen No. 4 & 0,913 & 0,284 & Valid \\
Instrumen No. 5 & 0,921 & 0,284 & Valid \\
Instrumen No. 6 & 0,928 & 0,284 & Valid \\
Instrumen No. 7 & 0,942 & 0,284 & Valid \\
Instrumen No. 8 & 0,942 & 0,284 & Valid \\
Instrumen No. 9 & 0,938 & 0,284 & Valid \\
Instrumen No. 10 & 0,915 & 0,284 & Valid \\
\hline
\end{tabular}

Sumber : Data Primer, diolah tahun 2018

Berdasarkan Tabel 5, dapat dilihat bahwa dari 10 butir pernyataan dari variabel kinerja karyawan hasilnya adalah valid.

\section{Uji Hipotesis}

1. Pengaruh
penempatan
karyawan

Tabel 6. Hasil Analisis Regresi Kompetensi dan Penempatan Terhadap Kinerja Karyawan
Dari hasil perhitungan koefisien korelasi skor tiap butir pernyataan instrumen kinerja karyawan dari 74 responden dengan jumlah pernyataan masing-masing variabel 10 pernyataan dengan total skor setiap responden hasil disajikan dalam Tabel 5

\begin{tabular}{|c|c|c|c|c|c|c|}
\hline \multicolumn{7}{|c|}{ Coefficients $^{a}$} \\
\hline \multirow{2}{*}{\multicolumn{2}{|c|}{ Model }} & \multicolumn{2}{|c|}{$\begin{array}{l}\text { Unstandardized } \\
\text { Coefficients }\end{array}$} & \multirow{2}{*}{$\begin{array}{c}\text { Standardized } \\
\text { Coefficients }\end{array}$} & \multirow[t]{2}{*}{$\mathrm{t}$} & \multirow[t]{2}{*}{ Sig. } \\
\hline & & $\mathrm{B}$ & Std. Error & & & \\
\hline \multirow{3}{*}{1} & (Constant) & 1.398 & .678 & & 7.985 & .000 \\
\hline & Kompetensi & 1.143 & .182 & .930 & 6.288 & .000 \\
\hline & Penempatan & .548 & .176 & .460 & 10.311 & .000 \\
\hline
\end{tabular}

$$
\text { Hasil analisis regresi }
$$
menjelaskan bahwa persamaan regresi yang disusun yaitu $\mathrm{Y}=1.398+1.143$ $\left(\mathrm{X}_{1}\right)+0.548\left(\mathrm{X}_{2}\right)$. Koefisien regresi variabel $\mathrm{X}_{1}$ bertanda positif menunjukkan adanya hubungan yang positif dari variabel kompetensi yang menyebabkan kenaikan sebesar 1.143 terhadap kinerja karyawan. Hal ini menunjukkan dengan adanya peningkatan kompetensi karyawan di 
PT. Alam Sutera Realty Tbk maka Kinerja karyawan dapat meningkat. Koefisien regresi variabel $\mathrm{X}_{2}$ bertanda positif menunjukkan adanya hubungan positif dari variabel penempatan yang menyebabkan kenaikan sebesar 0.548 terhadap kinerja karyawan. Hal ini menunjukkan dengan adanya keberhasilan penempatan karyawan di PT. Alam Sutera Realty Tbk dapat meningkatkan Kinerja karyawan.

Nilai F hitung sebesar 16,871, dapat diartikan terdapat pengaruh secara signifikan kompetensi dan penempatan terhadap kinerja karyawan di PT. Alam Sutera Realty Tbk.

\section{Pengaruh parsial kompetensi terhadap kinerja karyawan}

Tabel 7. Hasil Analisis Regresi Sederhana Kompetensi Terhadap Kinerja Karyawan

\begin{tabular}{|c|c|c|c|c|c|}
\hline \multicolumn{6}{|c|}{ Coefficients $^{a}$} \\
\hline & \multicolumn{2}{|c|}{$\begin{array}{l}\text { Unstandardized } \\
\text { Coefficients }\end{array}$} & \multirow{2}{*}{$\begin{array}{c}\begin{array}{c}\text { Standardized } \\
\text { Coefficients }\end{array} \\
\text { Beta }\end{array}$} & \multirow[t]{2}{*}{$\mathrm{t}$} & \multirow[t]{2}{*}{ Sig. } \\
\hline & $\mathrm{B}$ & Std. Error & & & \\
\hline Model & 1.373 & .660 & & 8.055 & .000 \\
\hline Kompetensi & 1.198 & .040 & .975 & 30.179 & .000 \\
\hline
\end{tabular}

Hasil analisis regresi sederhana menjelaskan bahwa persamaan regresi yang disusun yaitu $\mathrm{Y}=1.373+1.198$ $\left(\mathrm{X}_{1}\right)$. Koefisien regresi variabel $\mathrm{X}_{1}$ bertanda positif menunjukkan adanya hubungan positif dari variabel kompetensi yang menyebabkan kenaikan sebesar 1.198 terhadap kinerja karyawan. Hal ini menunjukkan keberhasilan peningkatan kompetensi karyawan di PT. Alam Sutera Realty Tbk maka kinerja karyawan akan semakin meningkat. Nilai $t$ hitung sebesar 30.179 dan $t$ Tabel sebesar 1.684 atau $t$ hitung > t Tabel (30.179> 1.684), maka dapat diartikan bahwa terdapat pengaruh yang signifikan variabel kompetensi terhadap kinerja karyawan PT. Alam Sutera Realty Tbk.

\section{Pengaruh parsial penempatan terhadap kinerja karyawan}

Tabel 8. Hasil Analisis Regresi Sederhana Penempatan Terhadap Kinerja Karyawan

\begin{tabular}{|c|c|c|c|c|c|c|}
\hline \multicolumn{7}{|c|}{ Coefficients $^{a}$} \\
\hline \multirow{2}{*}{\multicolumn{2}{|c|}{ Model }} & \multicolumn{2}{|c|}{$\begin{array}{c}\text { Unstandardized } \\
\text { Coefficients }\end{array}$} & \multirow{2}{*}{$\begin{array}{c}\begin{array}{c}\text { Standardized } \\
\text { Coefficients }\end{array} \\
\text { Beta }\end{array}$} & \multirow[t]{2}{*}{$\mathrm{t}$} & \multirow[t]{2}{*}{ Sig. } \\
\hline & & B & $\begin{array}{l}\text { Std. } \\
\text { Error }\end{array}$ & & & \\
\hline \multirow{2}{*}{1} & (Constant) & 1.585 & .220 & & 5.220 & .000 \\
\hline & Penempatan & 1.135 & .052 & .953 & 21.766 & .000 \\
\hline
\end{tabular}

Hasil analisis regresi sederhana menjelaskan bahwa persamaan regresi yang disusun yaitu $\mathrm{Y}=1.585+1.135$ $\left(\mathrm{X}_{2}\right)$. Koefisien regresi variabel $\mathrm{X}_{2}$ bertanda positif menunjukkan adanya hubungan positif dari variabel penempatan terhadap kinerja karyawan. Hal ini menunjukkan dengan adanya keberhasilan program penempatan karyawan di PT. Alam Sutera Realty Tbk akan meningkatkan Kinerja karyawan.

Nilai $t$ hitung seb3esar 21.766 dibandingkan dengan $\mathrm{t}$ Tabel sebesar 1.684 atau $\mathrm{t}$ hitung $>\mathrm{t}$ Tabel $(21.766>1.684)$, maka dapat diartikan bahwa terdapat pengaruh yang signifikan penempatan terhadap Kinerja karyawan PT. Alam Sutera Realty Tbk.

\section{KESIMPULAN DAN SARAN}

\section{Kesimpulan}

Mengacu dari latar belakang masalah penelitian yang telah diuraikan di muka bahwa hal yang melatarbelakangi penelitian ini adalah untuk meneliti seberapa besar kompetensi dan penempatan yang selama ini berkembang mempengaruhi kinerja karyawan PT. Alam Sutera Realty Tbk, selanjutnya apakah kebijakan peningkatan kompetensi dan penempatan karyawan tersebut perlu untuk diperbaiki atau sebaliknya. Melalui hasil analisa dan pembahasan 
penelitian tentang kompetensi dan penempatan dikaitkan dengan kinerja karyawan PT. Alam Sutera Realty Tbk, diperoleh beberapa kesimpulan yang dapat menjawab pertanyaan. Kesimpulan itu adalah sebagai berikut: 1). Hasil penelitian menunjukkan bahwa kompetensi dan penempatan berpengaruh secara simultan terhadap kinerja karyawan PT. Alam Sutera Realty Tbk. Hal ini berarti bahwa makin tinggi keberhasilan peningkatan kompetensi karyawan dan penempatan karyawan, maka makin baik kinerja individu karyawan. 2). Hasil penelitian menunjukkan bahwa kompetensi berpengaruh terhadap kinerja karyawan PT. Alam Sutera Realty Tbk. Hal ini berarti bahwa makin tinggi kompetensi karyawan, maka makin baik kinerja karyawan. 3). Hasil penelitian menunjukkan bahwa penempatan berpengaruh terhadap kinerja karyawan PT. Alam Sutera Realty Tbk. Hal ini berarti bahwa makin baik program penempatan karyawan, maka makin baik kinerja karyawan.

\section{Saran}

Setelah mengetahui pengaruh yang diberikan oleh variabel kompetensi dan penempatan terhadap kinerja karyawan pada PT. Alam Sutera Realty Tbk. Pada kesempatan ini peneliti mencoba untuk memberikan saran yang sekiranya dapat dijadikan rekomendasi khususnya bagi manajemen PT. Alam Sutera Realty Tbk, yang dijadikan objek penelitian, maupun perusahaan sejenis dalam mengambil kebijakan-kebijakan untuk peningkatan kinerja karyawannya: 1). Untuk faktor kompetensi, diharapkan perusahaan dalam meningkatkan kinerja karyawannya dengan cara terus memberikan pelatihan bagi karyawan, sehingga dengan diberikan pelatihan maka kompetensi karyawan dapat meningkat. 2). Pada faktor penempatan diharapkan manajemen dapat objektif dalam menempatkan karyawan karena akan memberikan dampak bagi kinerja karyawan. Ketidak sesuaian posisi jabatan yang ditawarkan dengan kemampuan dan minat yang dimiliki akan memberikan dampak langsung bagi tinggi rendahnya hasil kerja karyawan dalam mengemban pekerjaan yang diberikan kepadanya.

\section{DAFTAR PUSTAKA}

Al Rasyid. Harun. 2002. Teknik Penarikan Sampel dan Penyusunan Skala. Program Pascasarjana Universitas Padjadjaran. Bandung.

Arikunto, Suharsimi., 2009. Prosedur Penelitian Suatu Pendekatan Praktek, Rineka Cipta. Jakarta.

Dharma, Surya., 2009. Manajemen Kinerja Falsafah Teori dan Penerapannya. Pustaka Pelajar. Yogyakarta.

Hadari Nawawi., 2006. Evaluasi dan Manajemen Kinerja di Lingkungan Perusahaan dan Industri. Gadjah Mada University Press. Yogyakarta.

Hartel, Charmine E.J. dkk., 2007. Human Resource Management. Pearson Education. Australia.

Hutapea, Parulian dan Nurianna Thoha., 2008. Kompetensi Plus. PT Gramedia Pustaka Utama. Jakarta.

Justine Sirait., 2007. Memahami Aspekaspek Pengelolaan Sumber Daya Manusia dalam Organisasi. PT. Grasindo. Jakarta.

Mangkunegara. A.A. Prabu. Anwar. 2009. Manajemen Sumber Daya Manusia Perusahaan. Penerbit Remaja Rosdakarya. Bandung.

Mondy, R. Wayne. 2008. Manajemen Sumber Daya Manusia. Penerbit Erlangga. Jakarta.

R. Palan , 2007. Competency Management. PPM Indonesia. Jakarta. 
Rivai, Veithzal. \& Sagala, Ella. Jauvani., 2009. Manajemen Sumber Daya Manusia Untuk Perusahaan. Rajagrafindo Persada. Jakarta.

Rivai, Veithzal., 2008. Manajemen Sumber Daya Manusia untuk Perusahaan. PT. Remaja Rosda Karya. Bandung.

Siagian, P. Sondang., 2008. Manajemen Sumber Daya Manusia, Bumi Aksara. Jakarta.

Siagian, P. Sondang., 2005. Manajemen Stratejik, Edisi Keenam, PT. Bumi Aksara, Jakarta.

Sugiyono., 2009. Metode Penelitian Kuantitatif, Kualitatif dan $R \& D$. Alfabeta. Bandung.

Sugiyono., 2007. Metode Penelitian Kuantitatif Kualitatif dan R\&D. Alfabeta. Bandung.

Sugiyono, 2001, Metode Penelitian Administrasi, ALFABETA, Bandung.

Teguh, Ambar, Sulistiyani dan Rosidah., 2009. Manajemen Sumber Daya Manusia, Konsep Teori dan Pengembangan Dalam Konteks Organisasi Publik. Graha Ilmu. Yogyakarta.

Teguh, Ambar, Sulistiyani dan Rosidah., 2003. Manajemen Sumber Daya Manusia. Graha Ilmu. Yogyakarta.

Tjutju Yuniarsih dan Suwanto., 2009. Manajemen Sumber Daya Manusia, CV. Alfabeta. Bandung.

Travers., 1978. Elementary Survey Sampling. New York. Wadsworth Pub. Co.

Umar, Husein., 2008. Metode Penelitian untuk Skripsi dan Tesis Bisnis. Edisi Kedua. PT RajaGrafindo Persada. Jakarta.

Umar. Husein. 1998. Riset Sumber Daya Manusia Dalam Organisasi. Cetakan Ketiga. PT. Gramedia Pustaka Utama. Jakarta.
Wibowo. 2010. Manajemen Kinerja. Rajawali Pres. Jakarta. 